\title{
Infecciones osteoarticulares en niños: experiencia de cinco años
}

\section{Osteoarticular infections in children: five-year experience}

\author{
Andrea Hänel K. ${ }^{1}$, Pilar Rodríguez ${ }^{2}$, Antonia Silva B. ${ }^{1}$, Gisela Meza M. ${ }^{1}$ y Cecilia Piñera M${ }^{1,2}$
}

'Depto. Pediatría y Cirugía Infantil Sede Sur. Facultad de Medicina, Universidad de Chile.

Unidad de Infectología Pediátrica, Hospital Dr. Exequiel González Cortés. Santiago, Chile.

Los autores declaran ausencia de conflictos de interés.

Sin financiamiento externo.

Recibido: 11 de diciembre de 2019 (segunda versión: 20 de octubre de 2020) / Aceptado: 23 de octubre de 2020

\section{Resumen}

Introducción: Las infecciones osteoarticulares (IOA) son consideradas una urgencia infectológica en niños. Los principales microorganismos causales son Staphylococcus aureus y Streptococcus pyogenes. Objetivo: Describir las características bio-demográficas y clínicas de pacientes de 2 meses a 15 años hospitalizados entre 2012 y 2017 con diagnóstico de IOA. Pacientes y Métodos: Estudio retrospectivo en un hospital pediátrico. Se revisaron fichas clínicas de pacientes internados con diagnóstico de IOA. Resultados: Se incluyó a 146 pacientes. Un 60,3\% fueron de sexo masculino, mediana de edad 3 años 11 meses. El síntoma más frecuente al ingreso fue dolor articular (90\%) y la mediana de PCR fue de $43 \mathrm{mg} / \mathrm{L}$. Se obtuvo identificación microbiológica en $48 \%$; de ellos, $67,8 \%$ S aureus $(10,2 \%$ resistentes a meticilina). El 94,5\% de los pacientes recibió de forma empírica $\beta$-lactámico anti-estafilocócico. Un 70,5\% de los niños requirió procedimiento quirúrgico. A las 72 h se observó respuesta clínica y a los 4,7 días descenso de parámetros inflamatorios de laboratorio. El 88\% de los pacientes cursó sin complicaciones. Conclusiones: Las IOA son más frecuentes en varones, el agente infeccioso más frecuentemente identificado fue $S$. aureus, por lo cual se sugiere inicio del esquema antimicrobiano con un $\beta$-lactámico anti-estafilocócico, ampliando cobertura en pacientes bajo 5 años de edad. A los 5 días del tratamiento antimicrobiano ya hay respuesta clínica y descenso de parámetros inflamatorios.

Palabras clave: infecciones osteoarticulares; pediatría; etiologías; proteína $\mathrm{C}$ reactiva.

\section{Abstract}

Background: Osteoarticular infections (IOA) are considered infectious emergencies. The main microorganisms isolated are Staphylococcus aureus and Streptococcus pyogenes. Aim: To describe demographic and clinical characteristics of patients from 2 months to 15 years old, hospitalized between the years 2012 and 2017 with IOA diagnosis. Methods: Retrospective study in a pediatric hospital. Clinical records of hospitalized patients with IOA were reviewed. Results: 146 met inclusion criteria. $60.3 \%$ of the patients were male, median age 3 years 11 months. The main symptom at admission was joint pain (90\%) and the median CRP was $43 \mathrm{mg} / \mathrm{L} .48 \%$ of the patients had microbiological identification; $67.8 \%$ were positive for Staphylococcus aureus (10.2\% SAMR). $94.5 \%$ of the sample received empirical antistaphylococcal beta-lactam treatment and $70,5 \%$ had a surgical intervention. Clinical response was observed 72 hours of beginning of treatment, and a decreased in inflammatory laboratory markers was observed at 4.7 days. $88 \%$ of patients attended without complications. Conclusions: IOA infections are more common in boys, $S$. aureus is the main isolated pathogen, so we suggest to initiate the antimicrobial scheme with an antistaphylococcal beta-lactam, adding broad spectrum antimicrobial in children under 5 years. After 5 days of treatment, clinical resolution and decreased inflammatory laboratory parameters were observed.

Keywords: osteoarticular infections; pediatrics; etiology; C reactive protein

\section{Correspondencia a:}

Andrea Catalina Hänel Kirsten

ahanelk@gmail.com 
ciones de los pacientes internados en los servicios de Pediatría, Unidad de Paciente Crítico (UPC), Cirugía y Traumatología del Hospital de Niños Dr. Exequiel González Cortés (HEGC), entre enero 2012 y diciembre 2017. El estudio fue aprobado previamente por la Unidad de Docencia e Investigación del HEGC.

Se revisaron las fichas de los pacientes seleccionados según sus diagnósticos de egreso: códigos CIE-10 (artritis piógena (M00), infecciones directas de la articulación en enfermedades infecciosas y parasitarias clasificadas en otra parte $\left(\mathrm{M} 01^{*}\right)$, osteomielitis (M86), osteopatías en enfermedades clasificadas en otra parte (M90) y se ingresaron aquellas que cumplían dichos criterios. Se obtuvieron datos bio-demográficos (edad, sexo), clínicos (síntomas y signos al ingreso y durante la evolución), diagnóstico de ingreso y egreso, manejo (antimicrobianos, cirugía), variables de laboratorio e imágenes y complicaciones. Los datos fueron registrados en una planilla $\mathrm{ad}$ hoc, asignando un código a cada paciente, resguardando así la confidencialidad de los datos obtenidos.

\section{Criterios de inclusión}

Pacientes entre dos meses y 14 años 11 meses 29 días de edad, hospitalizados en los todos los servicios de Pediatría-HEGC, exceptuando el Servicio de Oncología, con los diagnósticos de AS, OM u osteoartritis aguda y subaguda.

\section{Criterios de exclusión}

Pacientes con alguna de las siguientes condiciones:

- Imunosuprimidos o antecedente de enfermedad del tejido conectivo o debut de ésta como mono o poliartritis.

- IOA asociadas a fractura expuesta o puerta de entrada para el desarrollo de infección.

- Cirugías osteo-articulares previas de la zona afectada, independiente del tiempo de evolución, con o sin material de osteosíntesis.

- IOA crónica: aquellos pacientes con manifestación clínica $>30$ días previo al ingreso.

- Pacientes con ficha clínica no disponible.

\section{Variables a estudiar}

- Bio-demográficas: género, edad, peso.

- Estacionalidad (mes de hospitalización).

- Co-morbilidades: respiratorias, neurológicas.

- Cuadro clínico: tiempo de evolución, signos y síntomas, hospitalizaciones previas por el mismo cuadro, número de consultas previas. Al ingreso: signos $\mathrm{y}$ síntomas, signos vitales, examen físico, diagnóstico. Evolución intrahospitalaria: servicio y días de hospitalización, días de uso de antimicrobianos (EV y VO), signos y síntomas diarios y número y día de intervenciones. Complicaciones asociadas a la IOA.
Estudio retrospectivo, descriptivo, de las características bio-demográficas y clínicas, tratamientos y complicaZunino y cols. ${ }^{8}$, Arnold y cols. ${ }^{10}$ ), este trabajo tiene como objetivo la descripción de las características epidemiolóclinicas y etiológicas de pacientes de dos los años 2012 y 2017, con diagnóstico IOA.

\section{Pacientes y Métodos}


- Exámenes de laboratorio al ingreso: PCR, recuento de leucocitos, VHS; microbiológicos: HC, cultivo de líquido articular, cultivo de tejido), y estudio por imágenes: Rx, cintigrama óseo, resonancia magnética (RM), tomografía computarizada (TC) y ecografía.

- Diagnóstico de egreso AS, OM y otras artritis y localización del cuadro.

\section{Definiciones}

- Cultivos negativos: aquellos en que no se detectó crecimiento de algún microorganismo a las $72 \mathrm{~h}$ y aquellos en los que crecieron agentes que se consideraron como contaminación (Micrococcus, Staphylococcus coagulasa negativa, Bacillus sp.).

- Leucocitos: se catalogaron como normales, elevados y bajos. Para esto se dividió la muestra en rangos etarios ( $<2$ años, 2 a 6 años y $>6$ años) y se evaluaron valores

\begin{tabular}{|c|c|c|c|}
\hline & & $\mathbf{n}$ & $\%$ \\
\hline \multirow[t]{4}{*}{ Edad } & Mediana & 3 años $11 \mathrm{~m}$ & $\operatorname{RIC}(1,6-8,9)$ años \\
\hline & $<2$ años & 45 & 31 \\
\hline & 2 a 5 años & 35 & 24 \\
\hline & $>5$ años & 66 & 45 \\
\hline \multirow[t]{2}{*}{ Género } & Masculino & 88 & 60 \\
\hline & Femenino & 58 & 40 \\
\hline \multirow[t]{5}{*}{ Signos de ingreso } & Dolor & 134 & 92 \\
\hline & Impotencia funcional & 86 & 59 \\
\hline & Eritema & 69 & 47 \\
\hline & Fiebre & 43 & 39 \\
\hline & Rash & 40 & 27 \\
\hline \multicolumn{4}{|c|}{ Laboratorio de ingreso } \\
\hline \multirow[t]{4}{*}{ Leucocitos $^{1}$} & Leucopenia & 2 & 1 \\
\hline & Normal & 95 & 65 \\
\hline & Leucocitosis & 46 & 32 \\
\hline & Sin dato & 3 & 2 \\
\hline \multirow[t]{5}{*}{ VHS (mm/h) } & Mediana & 36 & \\
\hline & $\mathrm{RIC}$ & $(15-56)$ & \\
\hline & Rangos & & \\
\hline & $<20$ & 35 & 24 \\
\hline & $\geq 20$ & 101 & 69 \\
\hline \multirow[t]{6}{*}{$\mathrm{PCR}(\mathrm{mg} / \mathrm{L})$} & Mediana & 43 & \\
\hline & $\mathrm{RIC}$ & $(22-95)$ & \\
\hline & Rangos & & \\
\hline & $<20$ & 34 & 23 \\
\hline & $20-90$ & 75 & 51 \\
\hline & $\geq 90$ & 35 & 24 \\
\hline
\end{tabular}

para la edad. Se consideró para lactantes ( 2 años o menos) un recuento normal de 6.000 a 17.000 leucocitos/ $\mathrm{mm}^{3}$, niños de 2 a 6 años 5.500 a 15.000 y $>6$ años 4.500 a 13.500 basándose en rangos publicados ${ }^{12}$.

- Parámetros inflamatorios elevados: se consideró VHS $\geq 20 \mathrm{~mm} / \mathrm{h}$ y $\mathrm{PCR} \geq$ a $20 \mathrm{mg} / \mathrm{L}^{13}$.

\section{Análisis estadístico}

Se usó estadística descriptiva básica (promedio, moda, mediana, frecuencias y rango intercuartil) para las variables. Para la comparación de grupos se utilizó $\chi^{2}$ para variables discretas y U Mann Whitney considerando significativo $\mathrm{p}<0,05$. Se realizó una regresión lineal de los valores de PCR inicial y evolutivos de aquellos pacientes con PCR $\geq$ a 40 con un $\mathrm{r}^{2}>0,6$ y un IC de $95 \%$ para determinar número de días en que se observó una disminución de este valor.

\section{Resultados}

\section{Descripción general}

Durante los años 2012 a 2017, 163 pacientes cursaron con IOA. Se excluyeron 17 pacientes: nueve por fractura expuesta, cuatro por cirugía previa, cuatro por falta de información. Se analizó un total de 146 pacientes; de ellos, $60,3 \%$ era de sexo masculino. La mediana de edad fue 3 años 11 meses y el grupo etario con mayor incidencia fueron escolares $(45 \% \geq 5$ años).

Las IOA se distribuyeron equitativamente a través de todo el año, sin diferencias estadísticamente significativas en la frecuencia estacional (datos no exhibidos).

La vía de admisión al hospital fue en $87,7 \%$ a través del Servicio de Urgencia. Un 55,5\% de los pacientes consultó más de una vez previo a su admisión. Co-morbilidad estaba presente en $18 \%$, de éstas $12 \%$ era una patología pulmonar crónica.

Los síntomas más encontrados fueron dolor (90\%), fiebre $(65 \%)$ e impotencia funcional $(59 \%)$ con una mediana de evolución previo al ingreso de 4 días. En 39\% de la muestra se logró objetivar fiebre. Las características bio-demográficas y clínicas se detallan en la Tabla 1. La localización topográfica fue en $76 \%$ en los miembros inferiores y en $14,4 \%$ en los miembros superiores.

\section{Laboratorio al ingreso}

El $65 \%$ de los pacientes tenía recuento de leucocitos dentro de valores normales, $31,5 \%$ presentó leucocitosis y dos pacientes $(1,4 \%)$ leucopenia, de acuerdo a los valores normales según grupo etario. La VHS elevada se observó en $69,2 \%$ de los pacientes, con mediana $35 \mathrm{~mm} / \mathrm{h}$. La mediana de PCR fue de $43 \mathrm{mg} / \mathrm{L}$ (RIC $\mathrm{p}_{25-75}$ de 22,3-95,2). El 75,4\% tuvo valor de PCR elevada y sólo $24 \%$ obtuvo valores sobre $90 \mathrm{mg} / \mathrm{L}$ (Tabla 1). 
En los pacientes con $\mathrm{PCR}$ inicial $\geq$ a $40 \mathrm{mg} / \mathrm{L}$ se observó una disminución de $30 \%$ respecto de su valor inicial, a los 4,7 días del ingreso. Para este análisis se excluyó un paciente con PCR al día 18 de evolución, dado que reflejaba una nueva intercurrencia infecciosa (Figura 1).

Como apoyo diagnóstico, en $74 \%$ de los pacientes se realizó uno o más estudios de imágenes; radiografía en $54,1 \%$, ecografía en $20,5 \%$, cintigrama óseo en $22,6 \%$, $\mathrm{RM}$ en $17,8 \%$ y $\mathrm{TAC}$ en $4,1 \%$.

\section{Estudio microbiológico de las IOA}

En 121 pacientes (82,9\% de la muestra) se tomó uno o más cultivos (HC y/o cultivo de tejido y/o cultivo liquido articular), de los cuales $48 \%$ resultó positivo a algún microorganismo. El 40\% del total de la muestra tuvo identificación microbiológica. Del total de cultivos positivos, $67,8 \%$ fue $S$. aureus (10,2\% SARM), seguido de $11,9 \%$ $S$. pyogenes. Al diferenciar por edad, en pacientes bajo 5 años de edad, 54,2\% correspondió a $S$. aureus (SARM $4,2 \%), 12,5 \%$ (n: 3 casos) a Neisseria meningitidis y un caso de Haemophilus influenzae no tipificable. En los pacientes sobre 5 años de edad, 77,2\% correspondió a $S$. aureus (14,3\% SARM), dos casos de Salmonella sp y sólo un caso de $N$. meningitidis. Al comparar ambos grupos etarios y los microorganismos encontrados, la diferencia es estadísticamente significativa con $\mathrm{p}<0,024$ (Tabla 2). El cultivo que aportó mayor información respecto al diagnóstico etiológico fue fue el $\mathrm{HC}$, correspondiendo a $69,5 \%$ de las muestras positivas.

$\mathrm{Al}$ analizar los $\mathrm{HC}$ negativos por grupo etario, en los pacientes bajo 5 años de edad, $85 \%$ de los cultivos resultó negativo versus $56 \%$ en los $\geq$ de 5 años $(p<0,001)$ (Tabla 3).

Todos los pacientes con N. meningitidis correspondieron al serogrupo $\mathrm{W}$ confirmados por el Instituto de Salud Pública-ISP, mientras que para $S$. pneumoniae y Haemophilus no tipificable no se logró contar con los datos de serotipificación efectuada por dicho laboratorio de referencia.

\section{Manejo de las IOA}

La totalidad de los pacientes recibió terapia antimicrobiana, $65,1 \%$ recibió monoterapia $\mathrm{EV}$, de los cuales $95,8 \%$ fue con un $\beta$-lactámico anti-estafilocócico (cloxacilina o cefazolina), 2,1\% recibió ceftriaxona y 2,1\% clindamicina (dos casos c/u). En 80,3\% de los pacientes sobre 5 años de edad se indicó monoterapia inicial versus $53,8 \%$ en pacientes bajo esa edad ( $p<0,001)$. El 34,9\% restante recibió bi-terapia empírica; las combinaciones más frecuentes fueron: $\beta$-lactámico anti-estafilocócico + cefalosporina de $3^{\text {era }}$ generación (74,5\%), un $\beta$-lactámico anti-estafilocócico + aminoglucósido $(11,8 \%)$ y $\beta$-lactámico anti-estafilocócico + otro $\beta$-lactámico (11,8\%) (Tabla 4). Sumando mono y bi-terapia, 94,5\%

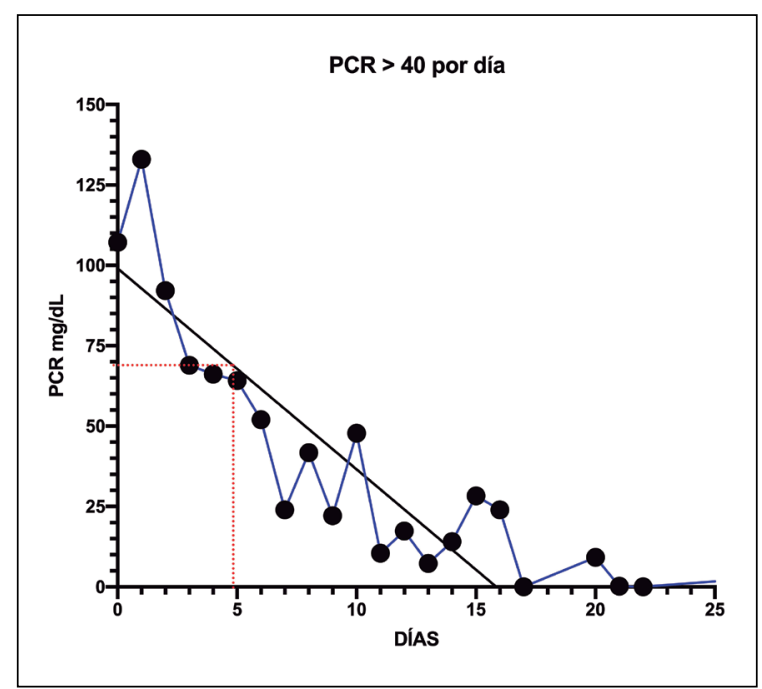

Figura 1. Regresión lineal PCR en pacientes con PCR $\geq 40 \mathrm{mg} / \mathrm{L}$ al ingreso.

\begin{tabular}{|c|c|c|c|c|c|}
\hline \multirow[t]{2}{*}{ Agente } & \multicolumn{2}{|c|}{$<5$ años } & \multicolumn{2}{|c|}{$\geq 5$ años } & \multirow{2}{*}{$\begin{array}{c}\text { Tota } \\
\%\end{array}$} \\
\hline & n & $\%$ & n & $\%$ & \\
\hline Staphylococcus aureus & 13 & 54,2 & 27 & 77,2 & 67,0 \\
\hline MS & 12 & 50,0 & 22 & 62,9 & 57,6 \\
\hline MR & 1 & 4,2 & 5 & 14,3 & 10,2 \\
\hline Streptococcus pyogenes & 2 & 8,3 & 5 & 14,3 & 11,9 \\
\hline Streptoccocus pneumoniae & 2 & 8,3 & 0 & 0,0 & 3,4 \\
\hline Salmonella sp & 2 & 8,3 & 2 & 5,7 & 6,8 \\
\hline Neisseria meningitidis grupo W & 3 & 12,5 & 1 & 2,9 & 6,8 \\
\hline Haemophilus no tipificable & 1 & 4,2 & 0 & 0,0 & 1,7 \\
\hline Pasteurella pneumotropica & 1 & 4,0 & 0 & 0,0 & 1,7 \\
\hline
\end{tabular}

Tabla 3. Estudio microbiológico en 146 niños con IOA

\begin{tabular}{|c|c|c|c|c|}
\hline & \multirow[t]{2}{*}{$\begin{array}{c}\mathrm{n}(\%) \\
\text { cultivos } \\
\text { realizados }\end{array}$} & \multicolumn{2}{|c|}{$\begin{array}{l}\text { \% positividad de los } \\
\text { cultivos realizados } \\
\text { por edad }\end{array}$} & \multirow[t]{2}{*}{$\begin{array}{l}\% \text { Total positividad } \\
\text { de los cultivos } \\
\text { realizados }\end{array}$} \\
\hline & & $<5$ años & $\geq 5$ años & \\
\hline Hemocultivos & $110(75)$ & $15^{*}$ & $44^{*}$ & 37,5 \\
\hline Cultivo de líquido articular & $82(56)$ & $\mathrm{NE}$ & NE & 24 \\
\hline Cultivo de tejidos & $54(40)$ & NE & NE & 22 \\
\hline \multirow[t]{2}{*}{ Total } & $121(83)$ & NE & NE & 49 \\
\hline & & & $\mathbf{n}$ & (\%) \\
\hline \multicolumn{3}{|c|}{ Total de pacientes con identificación microbiológica } & $59 / 146$ & 40,4 \\
\hline
\end{tabular}




\begin{tabular}{|c|c|c|c|c|c|c|}
\hline \multicolumn{7}{|c|}{ Duración en días* } \\
\hline & \multicolumn{2}{|c|}{ AS } & \multicolumn{2}{|c|}{$\mathrm{OM}$} & \multicolumn{2}{|c|}{ Total muestra } \\
\hline & Mediana & RIC & Mediana & RIC & Mediana & $\mathrm{RIC}$ \\
\hline $\mathrm{ev}+$ oral & 28 & $(21-35)$ & 31 & $(24,8-41)$ & 29,5 & $(23-38)$ \\
\hline ev & 9 & $(7-13)$ & 10,6 & $(7-13)$ & 9 & $(7-14)$ \\
\hline Oral & 22 & $(15-26)$ & 21 & $(15-28,5)$ & 21 & $(14-28)$ \\
\hline \multicolumn{7}{|c|}{ Esquema ATB primera línea por edad } \\
\hline & & $\begin{array}{c}<5 \text { años } \\
(\%)\end{array}$ & $\begin{array}{c}\geq 5 \text { años } \\
(\%)\end{array}$ & $\begin{array}{l}\text { Total } \\
(\%)\end{array}$ & & \\
\hline Monoterapia & & 53,8 & 80,3 & 65,1 & & \\
\hline Biterapia & & 46,3 & 24,5 & 34,9 & & \\
\hline \multicolumn{7}{|c|}{$\begin{array}{l}\text { *Sin diferencia significativa al separar por diagnóstico. **Biterapia: betaláctmico antiestafilocó- } \\
\text { cico + cefalosporina }(74,5 \%) \text { o aminoglicósido }(11,8) \text {; otro betaláctamico }(3,9) \text {; clindamicina } \\
\text { + betaláctamico }(5,9) ; 4 \% \text { betaláctamico. }\end{array}$} \\
\hline
\end{tabular}

Tabla 5. Evolución 146 pacientes con IOA

Duración de los síntomas

\begin{tabular}{lcccc} 
& Global & \multicolumn{3}{c}{ Fiebre } \\
& $\mathrm{N}$ & $(\%)$ & $\mathrm{N}$ & $(\%)$ \\
< 3 días & 138 & 61,3 & 41 & 58,8 \\
3 a 6 días & 61 & 27,1 & 18 & 25,7 \\
7 a 10 días & 13 & 5,8 & 4 & 5,7 \\
$\geq 10$ días & 13 & 5,8 & 7 & 10
\end{tabular}

Complicaciones (episodios)\#

Sin complicaciones

Eventos

Absceso/colección

Shock

Celulitis

Otro*

$\begin{array}{rl}N & (\%) \\ 129 & 88,4 \\ 10 & 43,7 \\ 5 & 21,7 \\ 3 & 13,0 \\ 5 & 21,6\end{array}$

Localización

Extremidad inferior
Extremidad superior
Columna/pelvis
Clavícula/hombro
ATM

Sin dato

$\begin{array}{rr}N & (\%) \\ 111 & 76,0 \\ 21 & 14,4 \\ 7 & 4,8 \\ 4 & 2,7 \\ 1 & 0,7 \\ 2 & 1,4\end{array}$

\#Pacientes > a un episodio: 11 años compromiso otra articulación y shock, 12 años falla orgánica múltiple, shock y absceso, 17 meses celulitis y colección, 2 años 10 meses celulitis y shock, 5 años compromiso otra articulación y falla renal, 11 años absceso, shock, trombosis venosa profunda (TVP). *otro: compromiso otra articulación $(N=2), \operatorname{TVP}(N=1)$, falla renal $(N=1)$, falla multiorgánica $(N=1)$. ATM: articulación temporo-mandibular. de la muestra recibió desde el ingreso un $\beta$-lactámico anti-estafilocócico.

$\mathrm{Al}$ egreso, a la totalidad de los pacientes se les prescribió antimicrobianos orales. Los principales antimicrobianos utilizados al alta fueron: 40,4\% flucloxacilina, $24,7 \%$ cefadroxilo, 9,6\% amoxicilina 5,5\% amoxicilina/ ácido clavulánico. Dos casos al alta tuvieron indicación de tratamiento antimicrobiano $\mathrm{EV}$ en forma ambulatoria.

La duración total de tratamiento antibacteriano fue de una mediana de 30 días $\left(\mathrm{RIC}_{\mathrm{p} 25-75}\right.$ 23-38 días). La mediana de duración de terapia EV fue de 9 días y VO de 21 días. Separando por diagnóstico, la duración (mediana) de antibioterapia para AS fue de 28 días $\left(\mathrm{RIC}_{\mathrm{p} 25-75} 21-35\right)$ y para $\mathrm{OM}$ de 31 días $\left(\mathrm{RIC}_{\mathrm{p} 25-75} 24,75-42\right)$ sin diferencia estadísticamente significativa.

En $70,5 \%$ de los niños se llevó a cabo un procedimiento quirúrgico; $72,8 \%$ de estas cirugías fueron en las primeras $24 \mathrm{~h}$ del cuadro, y $84,5 \%$ en las primeras $48 \mathrm{~h}$.

\section{Evolución clínica, de laboratorio y complicaciones}

La mediana de días de hospitalización en sala básica fue de 10 días. En $61,3 \%$ de la muestra los síntomas y signos duraron menos de tres días, en $88 \%$ cedieron a los seis días y sólo en 5,8\% persistieron $\geq 10$ días. El 58,3\% de los pacientes evolucionó afebril a partir del tercer día.

Se presentaron complicaciones agudas en $12 \%$ de la serie. Las complicaciones más frecuentes fueron absceso $(30 \%$; n: 7$)$, shock $(21 \%$; $: 5)$ y celulitis $(13 \%$; $: 3)$. El $6 \%$ (n: 6) de los pacientes requirió ingreso a UPC, con una mediana de dos días de permanencia. El detalle de la evolución se detalla en la Tabla 5. En nuestra serie no hubo pacientes fallecidos.

El diagnóstico de egreso fue en $45,2 \%$ osteomielitis y en $32,9 \%$ artritis séptica. El $51,4 \% \%$ de los pacientes egresó con el mismo diagnóstico de ingreso.

\section{Discusión y Conclusiones}

En el período de estudio observamos 146 IOA en niños. En nuestra serie se observó predominio del género masculino (60,3\%, con una relación masculino:femenino de $1,5: 1)$ lo que es similar a lo descrito en la literatura internacional ${ }^{1,14}$ y con una mayor tendencia que la anterior publicación chilena que reportó una relación de $1,04: 1^{11}$. En cuanto a distribución etaria, se vio una mayor incidencia en edad escolar ( $45 \%$ de los casos), difiriendo de lo descrito, tanto en una publicación extranjera-Grammatico-Guillon y cols. ${ }^{1}$ describen predominio en lactantes- como en el medio local, Prado y cols. ${ }^{11}$ no observaron diferencias por grupos etarios.

No se observaron diferencias en cuanto a estacionalidad del cuadro, explicable dado que no tiene relación con circulación de microorganismos con variaciones estacionales en su incidencia. 
con una importante menor detección SARM (sólo reportó un caso).

Al diferenciar por grupo etario, en los pacientes bajo 5 años de edad $52 \%$ de los pacientes tuvo como agente etiológico $S$. aureus y $38 \%$ otro microorganismo versus en aquellos $\geq 5$ años en que se aisló $S$. aureus en 77,2\% como agente etiologico. Las diferencias por edad son consistentes con literatura internacional. Moumile y cols. ${ }^{21}$, reportaron mayor prevalencia de otros microorganismos en niños bajo tres años de edad (75\%) versus una predominancia de $S$. aureus (62\%) en mayores de 36 meses. En Chile, Prado y cols. ${ }^{11}$ describieron predominancia de $S$. aureus sobre los seis años, en comparación con los pacientes bajo seis años de edad (aproximadamente 62 y $23 \%$, respectivamente) y predominancia de $S$. pyogenes en $<6$ años (aproximadamente 61 y 5,7\%, respectivamente). Al analizar los $\mathrm{HC}$ negativos, es significativa la mayor proporción de éstos en menores de 5 años $(85 \%)$ versus mayores de 5 años (56\%) lo que sería explicable por la ausencia de técnica microbiológicas recomendadas para estudio de bacilos gramnegativos fastidiosos, ni empleo de técnicas moleculares para $K$. kingae ${ }^{22}$, siendo que ese microorganismo podría ser el responsable hasta de $61 \%$ de las IAO globalmente ${ }^{23}$ y de $35 \%$ en pacientes bajo 3 años de edad $^{21}$. En la literatura médica nacional se observa la misma tendencia (HC negativos menores de 6 años $60 \%$ y mayores de 6 años 30\%, aproximadamente).

En cuanto al tratamiento antimicrobiano empírico, $94,5 \%$ de los pacientes en esta casuística recibió un $\beta$-lactámico anti-estafilocócico. Según nuestros hallazgos microbiológicos, no sería necesario cubrir empíricamente SARM dada la resistencia inferior a $15 \%$ en esta serie, lo que seguiría recomendaciones europeas ${ }^{7}$. Si comparamos inicio de monoterapia versus bi-terapia antimicrobiana en pacientes bajo 5 años de edad, sólo $46 \%$ recibió biterapia. Según lo ya mencionado anteriormente en la literatura médica, corroborado en los resultados de este trabajo, la indicación de antibioterapia empírica en niños bajo 5 años de edad debiera cubrir, junto a $S$. aureus sensible a meticilina (SASM), otros microrganismos prevalentes a esta edad, como $K$. kingae, $H$. influenzae, $N$. meningitidis entre otros. En cambio, en mayores de 5 años, 80,3\% recibió monoterapia como tratamiento empírico lo cual sería adecuado según el aislamiento microbiológico de nuestra serie y la literatura médica. En este último grupo se observó mayor resistencia antimicrobiana de $S$. aureus que en los pacientes bajo 5 años de edad.

Los plazos utilizados de antibioterapia, tanto intrahospitalario como al alta, fueron similares a las recomendaciones de la Sociedad Europea de Infectología Pediátrica (ESPID por sus siglas en inglés). No se observó diferencia estadística significativa al comparar duración de la antibioterapia en AS y OM (mediana 28 y 31, respectivamente). 
E1 21\% presentó alguna complicación aguda asociada a la infección siendo la más frecuente el absceso (30\%). Este valor es mayor al número establecido en publicaciones internacionales $^{24}$ (Karwowska y cols., 6,6\%) y nacionales ${ }^{11}$ (Prado y cols., 8,6\%); sin embargo, en las publicaciones mencionadas las complicaciones se describen como posteriores a la resolución del cuadro infeccioso, lo que no fue objetivo de este trabajo.

El diagnóstico de egreso predominante fue OM vs AS que no se condice con lo ampliamente publicado en la literatura médica ${ }^{1,11,17}$; contrariamente, la localización de las IOA observada, principalmente en extremidades inferiores seguido de extremidades superiores, es esperable según lo señala la literatura médica ${ }^{4,11}$.

Cabe destacar que existió un caso con aislamiento de SARM Panton Valantine positivo. Estas cepas se caracterizan por poseer mayor virulencia. La literatura médica internacional describe un aumento de su detección en la población pediátrica, y que produce infección con mayor morbi-mortalidad ${ }^{25}$. Requiere de alta sospecha y tratamiento antimicrobiano agresivo ${ }^{26}$. En este caso, se observó un comportamiento agresivo del microorganismo, que requirió el uso de tres agentes anti-estafilocócicos simultáneos por persistencia de cultivos positivos, mayor duración de la antibioterapia (30 días EV) y hospitalización (35 días), tres intervenciones quirúrgicas por persistencia de colecciones y un mayor número de complicaciones (neumonía por diseminación hematógena, TVP, abscesos, shock).

Limitaciones del presente estudio. Por su carácter retrospectivo, no podemos correlacionar los hallazgos clínicos con los análisis de laboratorio. Sin embargo, para el objetivo principal del trabajo, descripción epidemiológica de los pacientes con IOA, el análisis retrospectivo es suficiente para sacar conclusiones acerca de las características de la población analizada. Como fuera comentado con anterioridad, la falta de técnicas microbiológicas recomendadas para estudio de bacilos gramnegativos de crecimiento fastidioso - cultivo en medios enriquecidos-y realización de reacción de polimerasa en cadena (RPC) para $K$. kingae, podría explicar la falta de hallazgo de este microorganismo en esta muestra. Además, la ausencia de seguimiento a largo plazo de los pacientes con énfasis en la búsqueda de complicaciones tardías es una limitación para la detección de eventuales complicaciones.

En suma, los resultados sugieren que, dado que el microorganismo aislado más frecuentes es SASM, un esquema antimicrobiano EV con $\beta$-lactámico antiestafilocócico es la indicación como tratamiento empírico para esta población y se debe asociar a una cefalosporina $3^{\text {era }}$ generación para cobertura de especies gramnegativas en pacientes bajo 5 años de edad, acorde con las guías internacionales vigentes.

La duración del tratamiento EV podría acortarse a cinco días si hay resolución clínica y normalización del laboratorio, completando en total dos a tres semanas en AS y cuatro a seis semanas en OM.

Es necesario realizar estudios multicéntricos, prospectivos y randomizados, para evaluar plazos de terapia antimicrobiana más breves y seguimiento a largo plazo de las complicaciones, con el fin de estandarizar protocolos de manejo de los pacientes con IOA.

\section{Referencias bibliográficas}

1.- Grammatico-Guillon L, Maakaroun Vermesse Z, Baron S, Gettner S, Rusch E, Bernard L. Paediatric bone and joint infections are more common in boys and toddlers: a national epidemiology study. Acta Paediatrica 2013; 102 (3):e 120-5. doi: 10.1111/apa.12115.

2.- Moumile K, Merckx J, Glorion C, Pouliquen J C, Berche P, Ferroni A. Bacterial aetiology of acute osteoarticular infections in children. Acta Paediatrica. 2005; 94 (4): 419-22. doi: 10.1111/ j.1651-2227.2005.tb01911.x

3.- Arnold J C, Bradley J S. Osteoarticular infections in children. Infect Dis Clin North Am 2015; 29 (3): 557-74. doi: 10.1016/j. idc.2015.05.012.

4.- Calvo C, Núñez E, Camacho M, Clemente D, Fernández-Cooke E, Alcobendas R, et al. Epidemiology and management of acute, uncomplicated septic arthritis and osteomyelitis: Spanish multicenter study. Pediatr Infect Dis J. 2016; 35 (12): 128893. doi: 10.1097/INF.0000000000001309.

5.- Blyth M J G, Kincaid R, Craigen M A C, Bennet G C. The changing epidemiology of acute and subacute haematogenous osteomyelitis in children. Bone Joint J [Br] 2001; 83 (1): 99-102. doi: 10.1302/0301-620X.83B1.10699.

6.- Stockmann C, Ampofo K, Pavia AT, Byington C L, Blaschke A J, Sherwin C M, et al. National trends in the incidence, outcomes and charges of pediatric osteoarticular infections, 1997-2012. Pediatr Infect Dis J. 2015; 34 (6): 672-4 doi: 10.1097/ INF.0000000000000686.

7.- Saavedra-Lozano J, Falup-Pecurariu O, Faust SN, Girschick H, Hartwig N, Kaplan S, et al. Bone and joint infections. Pediatr Infect Dis J. 2017;36 (8): 788-99. doi: 10.1097/ INF.0000000000001635.

8.- Zuníno C, Vomero A, Pandolfo S, Gutiérrez C, Algorta G, Pírez C, et al. Etiología y evolución de las infecciones osteo-articulares. Hospital Pediátrico del Centro Hospitalario Pereira Rossell, Uruguay. Rev Chilena Infectol. 2017; 34 (3): 235-42. http://dx.doi.org/10.4067/ S0716-10182017000300005.

9.- $\quad$ Eich G F, Superti-Furga A, Umbricht F S, Willi U V. The painful hip: evaluation of criteria for clinical decision-making. Eur J Pediatr 1999; 158 (11): 923-8. doi:10.1007/s004310051243.

10.- Arnold S R, Elias D, Buckingham S C, Thomas E D, Novais E, Arkader A, et al. Changing patterns of acute hematogenous osteomyelitis and septic arthritis: emergence of communityassociated methicillin-resistant Staphylococcus aureus. J Pediatr Orthop. 2006; 26 (6): 703-8. doi: 10.1097/01.bpo.0000242431.91489.b4.

11.- Prado A, Lizama M, Peña A, Valenzuela C, Viviani T. Tratamiento intravenoso inicial abreviado en 70 pacientes pediátricos con infecciones osteo-articulares. Rev Chilena Infectol. 2008; 25 (1): 30-36. doi: 10.4067/ S0716-10182008000100007. 
12.- Dallman P R. Blood-forming tissues. In Rudolph AM (ed.): Pediatrics, 16th ed. New York, Appleton-Century-Crofts, 1977, p 1178.

13.- Pääkkönen M, Kallio M J T, Kallio P E, Peltola H. Sensivity of eritrocyte sedimentation rate and C-reactive protein in childhood bone and joint infections. Clin Orthop Relat Res. 2010; 468 (3): 861-6. doi: 10.1007/s11999-009-09361.

14.- Chiappini E, Camposampiero C, Lazzeri S, Indolfi G, De Martino M, Galli L. Epidemiology and management of acute haematogenous osteomyelitis in a tertiary paediatric center. Int J Environ Res Public Health. 2017; 14 (5): 477. doi: 10.3390/ ijerph14050477.

15.- Dartnell J, Ramachandran M, Katchburian M. Haematogenous acute and subacute paediatric osteomyelitis: a systematic review of the literature. J Bone Joint Surg Br. 2012; 94 (5): 584-95. doi: 10.1302/0301-620X.94B5.28523.

16.- Lorrot M, Fitoussi F, Faye A, Mariani P, JobDeslandre C, Penneçot G F, et al. Laboratory studies in pediatric bone and joint infections. Arch Pediatr. 2007; 14: S86-90. doi: 10.1016/ S0929-693X(07)80040-6.

17.- Rosanova MT, Berberian G, Bologna R, Giménez S, Sarkis C, Buchovsky A, et al. Estudio descriptivo de infecciones osteo-articulares en niños en tiempos de
Staphylococcus aureus resistente a meticilina de la comunidad (SARM-Co) Rev Chilena Infectol. 2015; 32 (3): 321-5. doi: 10.4067/ S0716-10182015000400010.

18.- Jaña-Neto F, Santori-Ortega C, De OliveiraGoiano E. Epidemiological study of osteoarticular infections in children. Acta Ortop Bras. 2008; 26 (3): 201-5. doi: 10.1590/1413785220182603145650.

19.- Chou A C, Mahadev A. The use of C-reactive protein as a guide for transitioning to oral antibiotics in pediatric osteoarticular infections. J Pediatr Orthop. 2016; 36 (2): 173-7. doi: 10.1097/BPO.0000000000000427.

20.- Peltola H, Pääkkönen M, Kallio P, Kallio M J T. Short- versus long-term antimicrobial treatment for acute hematogenous osteomyelitis of childhood: prospective, randomized trial on 131 culture-positive cases. Pediatr Infect Dis J 2010; 29 (12): 1123-8. doi: 10.1097/ INF.0b013e3181f55a89.

21.- Moumile K, Merckx J, Glorion C, Pouliquen J C, Berche P, Ferroni A. Bacterial aetiology of acute osteoarticular infections in children. Acta Paediatrica 2005; 94 (4): 419-22. https://doi. org/10.1080/08035250410023278.

22.- Von Graevenitz A, Zbinden R, Mutters R. Chapter 40: Actinobacillus, Capnocytophaga, Eikenella, Kingella, Pasteurella, and other fastidious or rarely encountered gram-negative rods. Murray PR, Baron EJ, Landry ML, Jorgensen JH, Pfaller MA editors. Manual of Clinical Microbiology, $9^{\text {th }}$ ed. Washington DC: ASM Press; 2007, p. 621-635.

23.- Chometon S, Benito Y, Chaker M, Boisset $\mathrm{S}$, Ploton C, Bérard J, et al. Specific realtime polymerase chain reaction places Kingella kingae as the most common cause of osteoarticular infections in young children. Pediatr Infect Dis J. 2007; 26 (5): 377-81. doi: 10.1097/01.inf.0000259954.88139.f4.

24.- Karwowska A, Davies HD, Jadavji T. Epidemiology and outcome of osteomyelitis in the era of sequential intravenous-oral therapy. Pediatr Infect Dis J. 1998; 17: 1021-6. doi: 10.1097/00006454-199811000-00012.

25.- Dohin B, Gillet Y, Kohler R, Lina G, Vandenesh F, Vanhems P, et al. Pediatric bone and joint infections caused by PantonValentine leukocidin-positive Staphylococcus aureus. Pediatr Infect Dis J. 2007; 26: 1042-8. doi: 10.1097/INF.0b013e318133a85e.

26.- Hawkshead J J, Patel N B, Steele RW, Heinrich S D. Comparative severity of pediatric osteomyelitis attributable to methicillin-resistant versus methicillinsensitive Staphylococcus aureus. J Pediatr Orthop 2009; 29 (1): 85-90. doi: 10.1097/ BPO.0b013e3181901c3a. 